Destruir la creación es decir a Dios: "no me gusta, esto no es bueno". ¿Y qué te gusta a ti? Me gusto a mí mismo: ¡Este es el pecado! La custodia de la creación es precisamente la custodia del don de Dios.

Hemos de respetar la creación. Custodiarla, porque si nosotros destruimos la creación, la creación nos destruirá. Este cuidado exige en primer lugar, el cuidado y respeto por la persona humana, creada a imagen de Dios. Respetar su identidad, comprender su realidad existencial y acompañarla para que logre sus nobles ideales y legítimas aspiraciones.

L a comunidad científica, sin perder el rigor de su método, ha de reflexionar sobre el don de la ciencia para entender bien que la creación es el más hermoso regalo de $D$ ios.

Juan Roger Rodríguez Ruiz J EFE DE PUBLICACIONES

\title{
LAS REVISTAS DE INVESTIGACIÓN Y LA MISIÓN DE LA UNIVERSIDAD
}

En estos tiempos de masificación y proliferación universitaria, cuyo signo más visible, evidente y casi único, es la formación profesional y el aspecto lectivo, es lamentable comprobar cómo, pese a lo proclamado y pregonado, la investigación científica no alcanza, ni en magnitud, ni en extensión, ni en profundidad, la consideración y atención logradas por la actividad característica de la enseñanza-aprendizaje.

En el panorama impactante, incluso por la presencia de universidades en lugares jamás imaginados, con carencia de recursos, precaria infraestructura y con nivel académico discutible o muy bajo, no aparece de manera ostensible, el producto de las investigaciones; y los pocos autores que investigan y producen ciencia y cultura no encuentran el medio difusor disponible. Por eso las universidades peruanas no aparecen en los rankings internacionales que dan cuenta de las instituciones que realizan y producen investigación científica.

Varias universidades se afanan y fundan sus revistas de investigación, las cuales, una vez que empiezan a editarse rápidamente entran en un proce- 
so irregular y casi siempre desaparece la periodicidad que debiera distinguirlas. Muchas desaparecen después de unos pocos números por falta de producción, por la ausencia de estímulos a la investigación y por la falta de atención a tan importante aspecto que le conceden las instancias pertinentes de cada universidad.

Por eso resultó gratificante que hace unos cinco años, la U LADECH decidiera publicar IN CRESCENDO, la misma que en el poco tiempo de edición ha logrado una reconocida posición de liderazgo no solo en el mundo hemerográfico, sino de la propia universidad que la sustenta y produce. Por eso sería lamentable y de graves consecuencias en el ámbito intelectual y científico, que dejara de publicarse. Sería un GRAVE, GRAVÍSIM O ERROR, pues la probable determinación no puede justificarse por las ediciones electrónicas, las cuales tienen sus propios canales de expresión como respuesta a la aparición del lenguaje de la imagen, el color y el sonido, lo cual significa que el lenguaje se ha ensanchado y ampliado sus manifestaciones, ninguna de las cuales es superior o mejor que otras y ambas tienen su propia naturaleza y circuito humano, social e intelectual.

Lo repito, sería un grave error, porque la medida - de ser cierta- silenciaría voces y cerraría canales de expresión auténtica, más en consonancia con la naturaleza humana. Lo digo no solo como editor de esta revista, sino como estudioso, investigador, escritor, periodista y profesor universitario; sin embargo, como no soy elemento estructural interno de la ULADECH, me limito a decir mi palabra, que también es portadora de mi gratitud por la confianza depositada en mi persona durante el tiempo transcurrido en esta fascinante y entrañable aventura.

Pero, al margen de las personas que ocupan cargos y desempeñan funciones, lo importante es que IN CRESCE ND 0 no cancele su edición impresa. La pantalla, los colores, los sonidos, la comunicación electrónica es, sin duda, lo más moderno, impactante y sensorial, pero no necesariamente lo superior ni mejor, por lo que no puede sobreponerse, silenciar ni desplazar la edición escrita. Ojalá las instancias de gobierno de la ULADECH, en un amplio, sereno y desapasionado análisis, enmienden rumbos por el bien no solo de la revista, de los investigadores, sino de toda la institución universitaria que le otorga sustento, sentido y trascendencia.

Saniel E. L ozano Alvarado EDITOR CIENTÍFICO 